\title{
A novel system with positive selection for the chromosomal integration of replicative plasmid DNA in Corynebacterium glutamicum
}

\author{
Masato Ikeda' and Ryoichi Katsumata²
}

Author for correspondence: Masato Ikeda. Tel: +8183522 2518. Fax: +8183522 2466 .

1 Technical Research Laboratories, Kyowa Hakko Kogyo Co., Ltd, Hofu, Yamaguchi 747-8522, Japan

2 Laboratory of Animal Microbiology, Faculty of Agriculture, Tohoku University, Aobaku, Sendai 981-0914, Japan

\begin{abstract}
A simple system has been developed for generating Corynebacterium glutamicum strains containing stable replicative plasmids integrated into the chromosome via homologous recombination. The system is based upon extremely strong incompatibility between two plasmids, which cannot be comaintained even under antibiotic selective pressure. Integration of the resident plasmid that contained the trpD gene of $C$. glutamicum was achieved by introduction of a second plasmid and subsequent selection for the maintenance of both plasmids. Plasmid integrates positive for both plasmid markers were obtained at a frequency about $10^{-3}$ of the normal transformation frequency with selection for the maintenance of only the second plasmid. Southern analysis revealed that the integration had occurred through a single-crossover homologous recombination between the trpD regions of the host genome and the plasmid. On the basis of the Campbelltype integration, chromosome walking was attempted by using Escherichia coli replication origins that were also present in the integrated plasmid. The chromosomal DNA was digested, ligated, and used to transform E. coli, which enabled recovery of the expected adjacent genomic DNA regions. The plasmid integrate was stably maintained for $\mathbf{3 0}$ generations under non-selective culture conditions, suggesting that the integrated sequences carrying a replicon active in the host were maintained as a stable chromosomal insert in C. glutamicum.
\end{abstract}

Keywords: Corynebacterium glutamicum, integration, plasmid incompatibility

\section{INTRODUCTION}

Non-pathogenic Gram-positive Corynebacterium glutamicum and related bacteria are industrially important micro-organisms, used in the production of various amino acids (Kinoshita \& Nakayama, 1978). Aminoacid-producing strains of these bacteria have been constructed by random mutagenesis and screening procedures (Kinoshita \& Nakayama, 1978). The development of gene cloning systems for these bacteria (Katsumata et al., 1984; Ozaki et al., 1984; Santamaria et al., 1984; Yoshihama et al., 1985) has enabled us to carry out further strain improvement. Several examples have already been reported of successful metabolic engineering of amino acid producers (Ikeda \& Katsumata, 1992; Ikeda et al., 1993, 1994).

Plasmid-mediated amplification of the gene for the ratelimiting enzyme is a common strategy in metabolic engineering. Plasmids generally carry antibiotic-resist- ance genes, which allow for selection, but these genes are not always maintained in the absence of the selective pressure (Katsumata \& Ikeda, 1993). In addition, overexpression of a plasmid-borne gene can markedly inhibit the growth of the host cells owing to metabolic imbalance or accumulation of intermediates (Aiba et al., 1982; Archer et al., 1991; Sugiura et al., 1987). Thus the integration of genes into the chromosome rather than via recombinant plasmids may be more useful for generating production strains for industrial-scale fermentation processes.

In bacteria, the most straightforward approach to integration relies on a non-replicating plasmid which carries a homologous chromosomal DNA segment and an antibiotic-resistance marker (Gutterson \& Koshland, 1983; Leenhouts et al., 1989). Introduction of such a plasmid yields transformants when a single crossover between the plasmid and the recipient chromosome occurs at the region of homology, which results in 
integration of the entire plasmid flanked by copies of the homologous DNA. This Campbell-type integration event was first demonstrated in the corynebacteria by Schwarzer \& Pühler (1991). They succeeded in selecting for plasmid integrates that resulted from highly efficient conjugal transfer from Escherichia coli to C. glutamicum of mobilizable $E$. coli vector plasmids carrying $C$. glutamicum DNA fragments. One limitation of this approach is the presence of strong restriction barriers in corynebacteria (Katsumata et al., 1984; Smith et al., 1986), although Reyes et al. (1991) and Vertès et al. (1993) described methods suitable for chromosomal integration in the highly restrictive corynebacteria.

Single-crossover integration of a plasmid after transformation generally occurs at a low frequency in the corynebacteria when the plasmid carries chromosomal sequences. To select for the plasmid integrates, we have devised a simple and efficient method based on extremely strong incompatibility between two plasmids. It is well known that two or more co-resident plasmids that have identical nucleotide sequences for all regions involved in replication and maintenance, which are referred to as isologous plasmids, are not stably inherited without external selection (Novick, 1987). However, preliminary studies described herein revealed that two vector plasmids which have the same pCG1 replication origin but differ in their antibiotic resistance markers could not be co-maintained in a C. glutamicum strain even under antibiotic selective pressure. This phenomenon prompted us to employ the two strictly incompatible plasmids to generate a C. glutamicum strain containing a replicative plasmid integrated into the chromosome via homologous recombination. If the resident plasmid contains sequences homologous to the chromosome, it should be possible to positively select for plasmid integrates existing at a certain frequency simply by the introduction of a second plasmid and subsequent selection for both plasmid markers. This method employs host-modified replicative plasmids and thus does not require any steps to overcome the restriction barriers.

We report here the use of extremely strong incompatibility between the two plasmids to generate Campbell-type integration of a replicative plasmid with the $\operatorname{trpD}$ gene into the C. glutamicum genome. The stability of the recombinants and the facile recovery of adjacent genomic DNA regions containing the other tryptophan-biosynthetic genes is also reported.

\section{METHODS}

Bacterial strains, plasmids and media. The strains and plasmids used in this study are listed in Table 1. C. glutamicum TA2 was isolated by selection for tryptophan auxotrophy after mutagenesis of strain L22 with NTG. The genetic lesion was identified as $\operatorname{trpD}$ by both enzyme assay and complementation analysis with the intact trpD gene of the organism. Plasmids pCG1 and pCG2 are endogenous cryptic plasmids isolated from C. glutamicum ATCC 31808 and ATCC 31832, respectively, in our laboratories (Ozaki et al., 1984). Vector plasmid pCG17 was constructed by ligation of the cryptic plasmid pCG2 and the $\mathrm{Sp}^{\mathrm{r}}$ and $\mathrm{Sm}^{\mathrm{r}}$ determinants from another endogenous plasmid, pCG4 (Katsumata et al., 1984). For growth of C. glutamicum, complete medium BY (Katsumata et al., 1984), minimal medium MM (Ozaki et al., 1985) and enriched minimal medium MMYE (Katsumata et al., 1984) were used. Solid plates were made by the addition of $1.6 \%$ (w/v) Bacto-Agar (Difco). RCGA medium (Katsumata et al., 1984) containing tryptophan $\left(50 \mu \mathrm{g} \mathrm{ml}^{-1}\right)$ was used for regeneration of C. glutamicum protoplasts. When required, supplements or antibiotics were added at the following final concentrations $\left(\mu \mathrm{g} \mathrm{ml}^{-1}\right)$ : spectinomycin $(\mathrm{Sp}), 400$ for RCGA plates or 100 for BY plates; kanamycin (Km), 200 for RCGA plates or 20 for BY plates; chloramphenicol $(\mathrm{Cm}), 5$ for BY plates; tetracycline (Tc), 2.5 for BY plates; streptomycin (Sm), 20 for BY plates; tryptophan, 50 for MM plates and MMYE medium. For growth of E. coli, LB medium (Sambrook et al., 1989) was used. For selecting transformants and examining their phenotypes, $\mathrm{Km}, \mathrm{Cm}$ or $\mathrm{Tc}$ was added at a final concentration of $20 \mu \mathrm{g} \mathrm{ml}^{-1}$ for LB plates.

Preparation and manipulation of DNA. Plasmid DNA of C. glutamicum was isolated by the alkaline lysis method (Sambrook et al., 1989) and, if necessary, purified by CsCl/ ethidium bromide equilibrium density-gradient centrifugation (Katsumata et al., 1984). Chromosomal DNA was extracted from protoplasts of C. glutamicum strains by the method of Saito \& Miura (1963). The protoplasts were prepared as described previously (Katsumata et al., 1984). Because of their lysozyme sensitivity, cells could be easily converted to protoplasts by lysozyme digestion without prior exposure to penicillin during growth. Preparation of plasmid DNA from $E$. coli, DNA digestion and ligation were carried out by standard procedures (Sambrook et al., 1989). Restriction enzymes and T4 DNA ligase were obtained from Takara Shuzo Co.

Transformations. Transformation procedures used were the protoplast method (Katsumata et al., 1984) for C. glutamicum and the $\mathrm{CaCl}_{2}$ method (Sambrook et al., 1989) for E. coli.

Southern hybridization. Digested chromosomal DNA was electrophoresed and transferred onto nitrocellulose membranes (Amersham), as described by Sambrook et al. (1989). Plasmid pCA45 was used as a hybridization probe; it was labelled to high specific activity with $\left[\alpha-{ }^{32} \mathrm{P}\right] \mathrm{dCTP}$ by the nicktranslation method (Rigby et al., 1977). The membranes were prehybridized for at least $2 \mathrm{~h}$ at $65^{\circ} \mathrm{C}$ and then hybridized overnight with the labelled probe at the same temperature. After being washed, the membranes were autoradiographed.

Determination of antibiotic resistance. C. glutamicum strains INT9 and TA2 carrying pCA45 were grown in $3 \mathrm{ml}$ BY medium supplemented with $\mathrm{Km}$. After appropriate dilutions of the culture broth, an aliquot $\left(10^{4}\right.$ cells $)$ was spread on BY plates containing various concentrations of the indicated antibiotics. Growth was assessed after $42 \mathrm{~h}$ incubation at $30^{\circ} \mathrm{C}$.

Stability of transformants. Seed cultures of C. glutamicum strains INT9 and TA2 carrying pCA45 grown in BYG medium (BY medium containing $1.0 \%$ glucose) were diluted in fresh BYG medium and grown for 30 generations aerobically at $30^{\circ} \mathrm{C}$. No differences in growth rate between the prototrophic strains and the plasmid-less tryptophan auxotroph were observed under the conditions used, confirming that there was no selection for the $\operatorname{trpD}$ gene in its mutant. After every ten generations, an aliquot was withdrawn from the culture and appropriate dilutions were spread on BY plates. After incubation at $30^{\circ} \mathrm{C}$ for $2 \mathrm{~d}, 100$ colonies from each sample were tested for their antibiotic-resistance phenotype. 
Table 1. Bacterial strains and plasmids

Strain or plasmid

Strains

C. glutamicum $\mathrm{L} 22$

C. glutamicum TA2

C. glutamicum INT9

E. coli MM294

Plasmids

pCE53

pCG11

pCG17

pCA45
Relevant characteristics

Lysozyme-sensitive mutant of wild-type ATCC 31833 ; no indigenous plasmids

$\operatorname{trpD}$ mutant of $\mathrm{L} 22$

TA2 containing pCA45 integrated into the chromosome supE44 bsdR endA1 pro thi

pCG1-ori, pACYC177-ori, $\mathrm{Km}^{\mathrm{r}} \mathrm{Cm}^{\mathrm{r}} \mathrm{Tc}^{\mathrm{r}}$

pCG1-ori, $\mathrm{Sp}^{\mathrm{r}} \mathrm{Sm}^{\mathrm{r}}$

pCG2-ori, $\mathrm{Sp}^{\mathrm{r}} \mathrm{Sm}^{\mathrm{r}}$

pCE53 derivative containing a $2 \cdot 1 \mathrm{~kb} t r p D$ fragment from

C. glutamicum $\mathrm{KY} 10894, \mathrm{Km}^{\mathrm{r}} \mathrm{Cm}^{\mathrm{r}} \mathrm{Tc}^{\mathrm{r}}$
Source or reference

Katsumata et al. (1987)

This study

This study

Sambrook et al. (1989)

Ozaki et al. (1984)

Katsumata et al. (1987)

This study

Katsumata \& Ikeda (1993); see Fig. 1

\section{RESULTS AND DISCUSSION}

\section{Incompatibility between C. glutamicum plasmid vectors}

Plasmid incompatibility was examined in C. glutamicum strain L22 using three multicopy vectors, pCE53 $\left(\mathrm{Km}^{\mathrm{r}}\right.$ $\left.\mathrm{Cm}^{\mathrm{r}} \mathrm{Tc}^{\mathrm{r}}\right)$, pCG11 $\left(\mathrm{Sp}^{\mathrm{r}} \mathrm{Sm}^{\mathrm{r}}\right)$ and $\mathrm{pCG} 17\left(\mathrm{Sp}^{\mathrm{r}} \mathrm{Sm}^{\mathrm{r}}\right)$. The former two have an identical pCG1 replication origin and the last has a pCG2 origin. Protoplasts of strain L22 carrying pCE53 were transformed with pCG11 or pCG17 and selected for $\mathrm{Sp}^{\mathrm{r}}$. Regenerated $\mathrm{Sp}^{\mathrm{r}}$ colonies were tested for the presence of $\mathrm{Km}^{\mathrm{r}}$. None of the pCG11carrying colonies checked had the $\mathrm{Km}^{\mathrm{r}}$ phenotype, whereas about $80 \%$ of the pCG17-carrying colonies were $\mathrm{Km}^{\mathrm{r}}$, indicating that pCE53 could be stably comaintained with pCG17, but not with pCG11. Hence, the isologous plasmids pCE53 and pCG11 were confirmed to be incompatible as predicted. Interestingly, double selection by $\mathrm{Km}^{\mathrm{r}}$ and $\mathrm{Sp}^{\mathrm{r}}$ after transformation of the pCE53 carrier with pCG11 gave no transformants, whereas with pCG17 the frequency was $2 \times 10^{5}$ per $10^{9}$ cells. This inability of pCE53 and pCG11 to co-exist even under antibiotic selective pressure indicated strong incompatibility between the two plasmids.

\section{Isolation of transformants possessing all selectable markers of two strictly incompatible plasmids}

When strain $\mathrm{TA2}$, a $\operatorname{trpD}$ mutant of L22, carrying pCE53 was transformed with pCG11 (100 ng DNA), $5 \times 10^{5}$ transformants were obtained upon selection for only $\mathrm{Sp}^{\mathrm{r}}$. However, as with the experiments with strain L22, no transformants appeared under selection for $\mathrm{Km}^{\mathrm{r}}$ and $\mathrm{Sp}^{\mathrm{r}}$. In contrast, transformation of strain TA2 carrying pCA45, a pCE53-derived plasmid that contained a $2 \cdot 1 \mathrm{~kb}$ fragment with the intact $\operatorname{tr} p D$ gene of $C$. glutamicum, with pCG11 gave about $10^{2} \mathrm{Km}^{\mathrm{r}} \mathrm{Sp}^{\mathrm{r}}$ transformants, corresponding to about $10^{-3}$ of the frequency for $\mathrm{Sp}^{\mathbf{r}}$ transformants. Similar results were obtained from two repeat experiments, confirming the reproducibility of the transformation. Ten randomly
Table 2. Antibiotic resistances of strains INT9, TA2 and TA2(pCA45)

MICs were determined as described in Methods.

\begin{tabular}{|lrrr|}
\hline \multirow{2}{*}{ Strain } & \multicolumn{3}{c|}{ MIC $\left(\mu \mathrm{g} \mathrm{ml}^{-1}\right)$} \\
\cline { 2 - 4 } & Km & Cm & Tc \\
\hline TA2(pCA45) & $>800$ & 50 & 6 \\
INT9 & 200 & 10 & 3 \\
TA2 & 0.4 & 1.6 & $0 \cdot 8$ \\
\hline
\end{tabular}

chosen clones from these $\mathrm{Km}^{\mathrm{r}} \mathrm{Sp}^{\mathrm{r}}$ transformants were purified by single-colony isolations and their phenotypes were examined. All clones tested showed a phenotype of $\mathrm{Km}^{\mathrm{r}} \mathrm{Cm}^{\mathrm{r}} \mathrm{Tc}^{\mathrm{r}}$, and prototrophy as well as $\mathrm{Sp}^{\mathrm{r}} \mathrm{Sm}^{\mathrm{r}}$, which indicated that they possessed all selectable markers of both plasmids. However, restriction cleavage analysis of the plasmids isolated from these clones allowed the detection of only pCG11 as a free plasmid, suggesting that the other plasmid, pCA45, had integrated into the host chromosome. Three such clones, chosen randomly, designated INT strains, were used for further analysis.

\section{Phenotypic and molecular analyses of INT strains}

If plasmid pCA45 was being integrated into the genome of INT strains in a Campbell-type manner, the resistance of cells to the plasmid-encoded antibiotics would be predicted to be lower in the putative single-copy plasmid integrates than in the multi-copy plasmid carrier. To examine this possibility, the MICs of $\mathrm{Km}, \mathrm{Cm}$ and $\mathrm{Tc}$ were compared between INT strains and TA2 carrying pCA45. The results obtained were almost as expected, which strongly suggested that the chromosomal integration of pCA 45 via a single-crossover recombination had occurred in INT strains. A typical result obtained with strain INT9 is given in Table 2. 


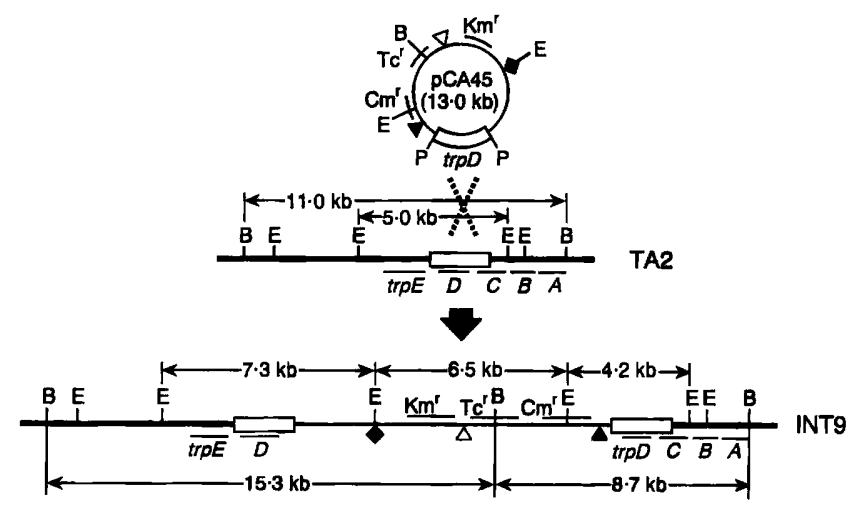

Fig. 1. Schematic representation of the relevant regions of the chromosomes of strains TA2 and INT9 after Campbell-type integration of plasmid pCA45. $\square$, Cloned $2.1 \mathrm{~kb}$ trpD fragment from C. glutamicum; $\diamond$, pCG1-ori; $\triangle$, pACYC177-ori; $\triangle$, pACYC184-ori. Restriction sites: B, BamHI; E, EcoRI; P, Pstl.

(a)

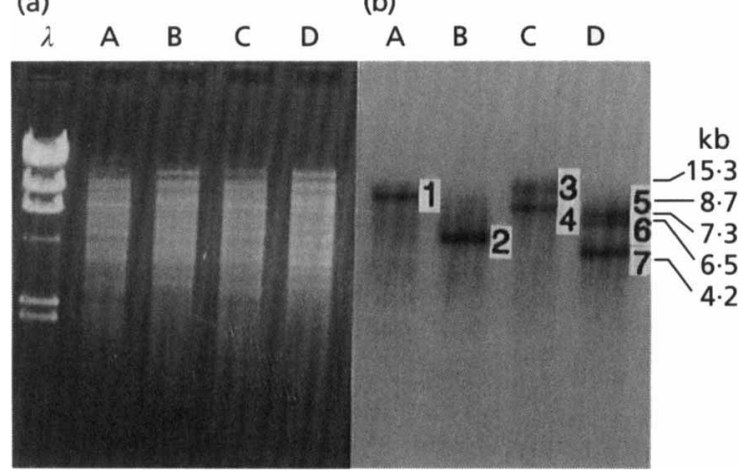

Fig. 2. Southern hybridization analysis of chromosomal DNAs from strains TA2 and INT9. (a) DNA samples on a $0.8 \%$ agarose gel. Lanes: $\lambda$, lambda HindIII size markers; $A$ and $B$, genomic DNA from strain TA2 digested with BamHI and ECORI, respectively; $C$ and $D$, genomic DNA from strain INT9 digested with BamHI and EcoRI, respectively. (b) Autoradiogram of a Southern blot of (a) (lanes A to D), hybridized with 32p-labelled pCA45. Numbers (1-7) in (b) indicate hybridizing bands. Sizes of bands $3-7$ are indicated on the right.

To verify the occurrence of a single crossover event and confirm the chromosomal structure of the plasmid integrate, genomic digests were analysed by Southern hybridization using ${ }^{32} \mathrm{P}$-labelled pCA45 as a probe. Probing genomic digests from the non-transformed host strain TA2 should give signals with sizes corresponding to those expected from the restriction cleavage map of the C. glutamicum tryptophan-biosynthetic gene cluster (Katsumata \& Ikeda, 1993) depicted schematically in Fig. 1. After Campbell-type integration, these hybridizing signals should be absent and followed by a shift to new signals in genomic digests from the plasmid integrate INT9 (Fig. 1). The results are presented in Fig. 2. As expected, the DNA from TA2 gave a unique band of $11.0 \mathrm{~kb}$ when digested with BamHI (Fig. $2 \mathrm{~b}$, lane A, band 1) and a $5.0 \mathrm{~kb}$ band when digested with EcoRI
(Fig. 2b, lane B, band 2). When genomic digests from INT9 were probed, band 1 disappeared in the BamHI digests and two hybridizing bands, of $15.3 \mathrm{~kb}$ and $8.7 \mathrm{~kb}$, were detected instead (Fig. 2b, lane C, bands 3 and 4). In addition, in the EcoRI digests, band 2 was replaced by three hybridizing bands, of $7 \cdot 3,6 \cdot 5$ and $4.2 \mathrm{~kb}$ (Fig. $2 \mathrm{~b}$, lane $D$, bands 5,6 and 7). The sizes of these five new bands (3-7) were in agreement with those expected after Campbell-type integration of pCA45 through a singlecrossover homologous recombination between the $\operatorname{tr} p D$ regions of the host genome and the plasmid. A similar analysis of two other INT strains revealed that in these strains also the plasmids were integrated via a Campbelltype mechanism (data not shown).

\section{Recovery of chromosomal regions flanking the integrated pCA45}

As shown in Fig. 1, the integrated vector flanked by a duplication of the $\operatorname{trpD}$ region contains two kinds of $E$. coli replication origins. Therefore, it should be possible to clone other tryptophan-biosynthetic genes into $E$. coli if the adjacent genomic DNA regions are rescued as circular molecules so that they contain either origin as well as one of the selectable markers through digestion with an appropriate restriction enzyme and subsequent self-ligation. To examine this possibility, BamHI was chosen as the restriction enzyme. Chromosomal DNA of strain INT9 was completely digested with BamHI and treated with T4 DNA ligase at high dilution to maximize intramolecular ligation and therefore circularization of each fragment. The ligation mixture was then used to transform competent cells of E. coli MM294. Transformants were selected for $\mathrm{Cm}^{\mathrm{r}}$ or $\mathrm{Km}^{\mathrm{r}}$ and their phenotypes determined. As expected from the chromosomal structure depicted in Fig. 3(a), the former and the latter transformants showed the $\mathrm{Cm}^{\mathrm{r}} \mathrm{Km}^{\mathrm{s}} \mathrm{Tc}^{\mathrm{s}}$ phenotype and the $\mathrm{Km}^{\mathrm{r}} \mathrm{Cm}^{\mathrm{s}} \mathrm{Tc}^{\mathrm{s}}$ phenotype, respectively. Restriction cleavage analysis (Fig. 3b) of each plasmid isolated from the former and the latter transformants and designated pEX1 and pEX2, respectively, yielded the same restriction cleavage map as that depicted in Fig. $3(\mathrm{a})$, indicating that $\mathrm{pEX} 1$ and $\mathrm{pEX} 2$ contained the $\operatorname{trp} C B A$ genes and the $\operatorname{tr} p E$ gene, respectively, in addition to the $\operatorname{trp} D$ gene. These results suggest that chromosomal sequences flanking any cloned genes of $C$. glutamicum could be obtained as plasmids by using the same procedure as described here. These plasmids can be physically analysed to give restriction maps of the flanking regions and then be used as a source of DNA fragments for subsequent cycles of cloning. Thus, this method should provide alternative tools not only for integrating replicative plasmids but for 'chromosome walking', which is useful for genomic studies in $C$. glutamicum.

\section{Stability of the chromosomal insert}

The segregational stability of the antibiotic-resistance phenotype was examined under non-selective culture conditions in both INT9 and TA2 carrying pCA45. The 
(a)
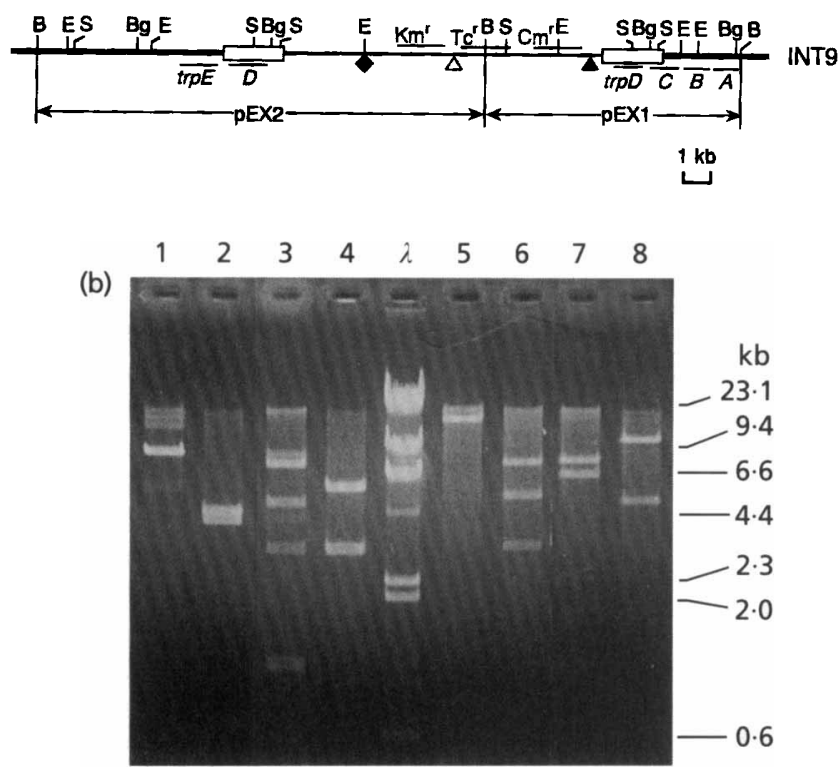

Fig. 3. Restriction cleavage analysis of excision plasmids $p E X 1$ and PEX2. (a) Predicted structure of genomic DNA regions yielding PEX1 and PEX2 after digestion of chromosomal DNA of strain INT9 with BamHI. Symbols are as described in the legend to Fig. 1. Restriction sites: B, BamHI; Bg, Bglll; E, EcoRI; S, Sall. (b) Restriction cleavage patterns of PEX1 (lanes 1-4) and PEX2 (lanes 5-8) on a $0.8 \%$ agarose gel. Each plasmid was digested with BamHI (lanes 1 and 5), EcoRI (lanes 2 and 6), Sall (lanes 3 and 7) or Bg/ll (lanes 4 and 8). The numbers on the right indicate the sizes of $\lambda$ DNA digested with Hindill. Faint bands visible were due to incomplete digestion of DNA. In lane 2 , the smallest (approx. $0.7 \mathrm{~kb}$ ) fragment is not visible, although it was present.

latter pCA45 carrier lost the $\mathrm{Km}^{\mathrm{r}}$ phenotype in proportion to the number of generations; about $60 \%$ of the colonies tested were $\mathrm{Km}^{\mathrm{s}}$ after 30 generations. In contrast, strain INT9 stably retained the $\mathrm{Km}^{\mathrm{r}}$ phenotype. Furthermore, the $\mathrm{Km}^{\mathrm{r}}$ segregants of INT9 after 30 generations all possessed the other phenotypes of $\mathrm{Cm}^{\mathrm{r}}$, $\mathrm{Tc}^{\mathrm{r}}$ and prototrophy.

Reyes et al. (1991) reported the integration of a replicondeleted and religated plasmid in Corynebacterium melassecola and demonstrated high segregational stability of the integrative transformants. They inferred that stable maintenance of the integrated insert in the organism might be attributed to the absence of a replicon, based on previous studies by Young \& Ehrlich (1989) and Leenhouts et al. (1990), which showed that plasmid replicative activity in integrated inserts led to their loss under non-selective growth conditions. However, our present study has demostrated high segregational stability of the chromosomal insert with a replicon active in the host for at least 30 generations, which is a larger number of generations than is used in industrial large-scale cultivation. This result demonstrates the feasibility of Campbell-type integration of replicative plasmid DNA to genetically manipulate C. glutamicum strains for industrial use.

\section{Concluding remarks}

Some research groups have used plasmid incompatibility to facilitate plasmid integration or gene replacement in bacteria, including E. coli (Simon et al., 1983) and Pasteurella haemolytica (Fedorova \& Highlander, 1997). In these studies, a rare recombination event was promoted through prolonged cultivation of cells where two incompatible plasmids were forced to co-exist. However, the last step was based on negative selection, because transformants that had been selected for both plasmid markers still consisted mostly of cells with two incompatible plasmids co-existing. In contrast, the system described here is based on a positive selection. To our knowledge, this is the first report of strong incompatibility being used to positively select transformants containing replicative plasmid DNA integrated into prokaryotic genomes. This system is efficient and thus should be a useful addition to the tools used in genetic engineering of the industrially important corynebacteria.

\section{ACKNOWLEDGEMENTS}

We are grateful to Yoshie Kaneko for her excellent technical assistance.

\section{REFERENCES}

Aiba, S., Tsunekawa, H. \& Imanaka, T. (1982). New approach to tryptophan production by Escherichia coli: genetic manipulation of composite plasmids in vitro. Appl Environ Microbiol 43, 289-297.

Archer, J. A. C., Solow-Cordero, D. E. \& Sinskey, A. J. (1991). A Cterminal deletion in Corynebacterium glutamicum homoserine dehydrogenase abolishes allosteric inhibition by L-threonine. Gene 107, 53-59.

Fedorova, N. D. \& Highlander, S. K. (1997). Generation of targeted nonpolar gene insertions and operon fusions in Pasteurella baemolytica and creation of a strain that produces and secretes inactive leukotoxin. Infect Immun 65, 2593-2598.

Gutterson, N. I. \& Koshland, D. E. (1983). Replacement and amplification of bacterial genes with sequences altered in vitro. Proc Natl Acad Sci USA 80, 4894-4898.

Ikeda, M. \& Katsumata, R. (1992). Metabolic engineering to produce tyrosine or phenylalanine in a tryptophan-producing Corynebacterium glutamicum strain. Appl Environ Microbiol 58, 781-785.

Ikeda, M., Ozaki, A. \& Katsumata, R. (1993). Phenylalanine production by metabolically engineered Corynebacterium glutamicum with the pheA gene of Escherichia coli. Appl Microbiol Biotechnol 39, 318-323.

Ikeda, M., Nakanishi, K., Kino, K. \& Katsumata, R. (1994). Fermentative production of tryptophan by a stable recombinant strain of Corynebacterium glutamicum with a modified serinebiosynthetic pathway. Biosci Biotechnol Biochem 58, 674-678.

Katsumata, R. \& Ikeda, M. (1993). Hyperproduction of tryptophan in Corynebacterium glutamicum by pathway engineering. Bio/ Technology 11, 921-925.

Katsumata, R., Ozaki, A., Oka, T. \& Furuya, A. (1984). Protoplast transformation of glutamate-producing bacteria with plasmid DNA. J Bacteriol 159, 306-311. 
Katsumata, R., Mizukami, T., Ozaki, A., Kikuchi, Y., Kino, K., Oka, T. \& Furuya, A. (1987). Gene cloning in glutamic acid bacteria: the system and its applications. In Proceedings of the 4th European Congress on Biotechnology, Amsterdam, vol. 4, pp. 767-776. Edited by O. M. Neijssel and others. Amsterdam: Elsevier.

Kinoshita, S. \& Nakayama, K. (1978). Amino acids. In Primary Products of Metabolism, pp. 209-261. Edited by A. H. Rose. London, New York \& San Francisco: Academic Press.

Leenhouts, K. J., Kok, J. \& Venema, G. (1989). Campbell-like integration of heterologous plasmid DNA into the chromosome of Lactococcus lactis subsp. lactis. Appl Environ Microbiol 55, $394-400$.

Leenhouts, K. J., Kok, J. \& Venema, G. (1990). Stability of integrated plasmids in the chromosome of Lactococcus lactis. Appl Environ Microbiol 56, 2726-2735.

Novick, R. P. (1987). Plasmid incompatibility. Microbiol Rev 51, 381-395.

Ozaki, A., Katsumata, R., Oka, T. \& Furuya, A. (1984). Functional expression of the genes of Escherichia coli in gram-positive Corynebacterium glutamicum. Mol Gen Genet 196, 175-178.

Ozaki, A., Katsumata, R., Oka, T. \& Furuya, A. (1985). Cloning of the gene concerned in phenylalanine biosynthesis in Corynebacterium glutamicum and its application to breeding of a phenylalanine producing strain. Agric Biol Chem 49, 2925-2930.

Reyes, O., Guyonvarch, A., Bonamy, C., Salti, V., David, F. \& Leblon, G. (1991). 'Integron'-bearing vectors: a method suitable for stable chromosomal integration in highly restrictive corynebacteria. Gene 107, 61-68.

Rigby, P. W. J., Dieckman, M., Rhodes, C. \& Berg, P. (1977). Labeling deoxyribonucleic acid to high specific activity in vitro by nick translation with DNA polymerase I. J Mol Biol 113, 237-251.

Saito, H. \& Miura, K. (1963). Preparation of transforming deoxyribonucleic acid by phenol treatment. Biochim Biophys Acta 72, 619-629.

Sambrook, J., Fritsch, E. F. \& Maniatis, T. (1989). Molecular
Cloning: a Laboratory Manual, 2nd edn. Cold Spring Harbor, NY : Cold Spring Harbor Laboratory.

Santamaria, R., Gil, J. A., Mesas, J. M. \& Martin, J. F. (1984). Characterization of an endogenous plasmid and development of cloning vectors and a transformation system in Brevibacterium lactofermentum. J Gen Microbiol 130, 2237-2246.

Schwarzer, A. \& Puhler, A. (1991). Manipulation of Corynebacterium glutamicum by gene disruption and replacement. Bio/Technology 9, 84-87.

Simon, R., Priefer, U. \& Puhler, A. (1983). A broad host range mobilization system for in vivo genetic engineering: transposon mutagenesis in gram negative bacteria. Bio/Technology 1, 784-790.

Smith, M. D., Flickinger, J. L., Lineberger, D. W. \& Schmidt, B. (1986). Protoplast transformation in coryneform bacteria and introduction of an $\alpha$-amylase gene from Bacillus amyloliquefaciens into Brevibacterium lactofermentum. Appl Environ Microbiol 51, 636-639.

Sugiura, M., Suzuki, S. \& Kisumi, M. (1987). Improvement of histidine-producing strains of Serratia marcescens by cloning of a mutant allele of the histidine operon on a mini-F plasmid vector. Agric Biol Chem 51, 371-377.

Vertès, A. A., Hatakeyama, K., Inui, M., Kobayashi, M., Kurusu, Y. \& Yukawa, H. (1993). Replacement recombination in Coryneform bacteria : high efficiency integration requirement for non-methylated plasmid DNA. Biosci Biotechnol Biochem 57, 2036-2038.

Yoshihama, M., Higashiro, K., Rao, E. A., Akedo, M., Shanabruch, W. G., Follettie, M. T., Walker, G. C. \& Sinskey, A. J. (1985). Cloning vector system for Corynebacterium glutamicum. J Bacteriol 162, 591-597.

Young, M. \& Ehrlich, S. D. (1989). Stability of reiterated sequences in the Bacillus subtilis chromosome. J Bacteriol 171, 2653-2656.

Received 12 December 1997; revised 24 February 1998; accepted 20 March 1998. 